\title{
REVISTA DO ENSINO/RS (1951-1961): UM OLHAR HISTÓRICO SOBRE AS DIRETRIZES DA EXPERIMENTAÇÃO NO ENSINO DE CIÊNCIAS
}

\author{
REVISTA DO ENSINO/RS (1951-1961): A HISTORICAL LOOK AT THE \\ GUIDELINES FOR EXPERIMENTATION IN SCIENCE TEACHING
}

\author{
VITOR GARCIA STOLL' \\ ALESSANDRO CARVALHO BICA ${ }^{2}$ \\ CADIDJA COUTINHO ${ }^{3}$ \\ TICIANE DA ROSA OSÓRIO
}

\section{RESUMO}

Este artigo analisa as propostas didáticas de experimentações contidas na Revista do Ensino do Rio Grande do Sul, no período de 1951-1961, a predominância disciplinar e os conteúdos científicos abordados pelas mesmas. 0 recorte temporal compreende o início da segunda fase de distribuição do periódico e a promulgação da Lei 4.024, que fixou as Diretrizes e Bases da Educação Nacional. Classifica-se quanto a natureza como qualitativa, sendo a abordagem técnico-metodológica embasada na Análise Documental. Os dados empíricos foram obtidos no Repositório Digital Tatu, vinculado a Universidade Federal do Pampa. Constatou-se a presença de experimentações em $82 \%$ dos exemplares, 120 experimentos: 56 direcionados a conteúdos de Biologia, 34 de Química e 30 de Física. Predominaram propostas com caráter empirista (86\%), pautadas em registros sistemáticos, replicabilidade e direcionadas a observação. Além disso, três exemplares apresentaram indícios de interdisciplinaridade, sendo os discursos sobre a temática intensificados no Brasil somente na década de 1960.

Palavras-chave: Educação Científica. Imprensa pedagógica. Pesquisa Documental.

\section{ABSTRACT}

This article analyzes the didactic proposals for experiments contained in the Revista do Ensino do Rio Grande do Sul, in the period 1951-1961, the disciplinary predominance and the scientific contents addressed by them. The time frame comprises the beginning of the second phase of distribution of the journal and the enactment of Law 4,024, which established the Guidelines and Bases of National Education. It is classified as nature as qualitative, with the technical-methodological approach based on Document Analysis. Empirical data were obtained from the Tatu Digital Repository, linked to the Federal University of Pampa. Experiments were found in $82 \%$ of the specimens, 120 experiments: 56 aimed at Biology, 34 Chemistry and 30 Physics content. Proposals with an empiricist character predominated (86\%), based on systematic records, replicability and directed to observation. In addition, three copies showed evidence of interdisciplinarity, and the speeches on the subject intensified in Brazil only in the 1960s.

Keywords: Science Education. Pedagogical press. Documentary Research.

\footnotetext{
1 Mestre em Ensino pela Universidade Federal do Pampa. Professor da rede municipal de Dom Pedrito. E-mail: vitorgarciastoll@gmail.com. Orcid: http://orcid.org/0000-0002-4133-9313.

2 Doutor em Educação pela Universidade do Vale dos Sinos. Professor Adjunto da Universidade Federal do Pampa. E-mail: alessandrobica@ gmail.com. Orcid: https://orcid.org/0000-0003-2532-5007.

3 Doutora em Educação em Ciências: Química da Vida e Saúde pela Universidade Federal de Santa Maria. Professora Adjunta da Universidade Federal do Pampa. E-mail: cadidjabio@gmail.com. Orcid: https://orcid.org/0000-0002-5182-7775.

4 Mestre em Ensino pela Universidade Federal do Pampa. E-mail: ticianidp@gmail.com. Orcid: https://orcid.org/0000-0003-1621-9077.
} 


\section{UM OLHAR SOBRE A REVISTA DO ENSINO/RS}

0 estudo aqui descrito vincula-se a Revista do Ensino do Rio Grande do Sul (RE/RS), importante artefato histórico da imprensa pedagógica, que teve sua trajetória distribuída em três fases de circulação: 1939-1942, 1951-1978 e 1989-1992 (BASTOS, 2005). Destinada, em geral, aos Ensinos Primário e Pré-primário, possuía como objetivo oferecer orientações didáticas, pedagógicas e metodológicas ao professorado gaúcho e brasileiro (BASTOS, 1997).

Iniciada como uma publicação regional, na segunda fase expandiu-se nacional e internacionalmente, tendo na década de 1970 tiragem superior a 55 mil exemplares. Circulava através do sistema de assinatura e venda avulsa, sendo publicados em média oito a dez números por ano, contendo cerca de 80 páginas cada (FARIA, 2017; PEREIRA, 2010; DUARTE 2009; BASTOS, 1997).

Em seu conteúdo, trazia orientações específicas e recursos visuais para serem utilizados em sala de aula nas diversas disciplinas do currículo, bem como, tratava de temas específicos, tais como, música, meio ambiente e datas comemorativas (PEREIRA, 2010; SARDAGNA, 2008). Além disso, publicava as mudanças nas regulamentações legais das políticas públicas da época, que geralmente eram comentadas e detalhadas. Enfatizava campanhas relacionadas à saúde, à educação sanitária, à educação de adultos, à leitura, dentre outras. Contava com a publicação de artigos científicos e depoimentos de profissionais de diversas áreas. E apresentava sugestões de bibliografias para 0 aprofundamento das temáticas que se desejava ensinar (WESCHENFELDER, 2003).

No que se refere ao Ensino de Ciências, conforme estudos anteriores (STOLL; BICA; COUTINHO, 2019), foram encontradas cinco seções específicas no período de 1951 a 1961, quais sejam: "Higiene", "Sugestões para o estudo dos animais", "Observando plantas", "Observando" e "Observações e experiências". A primeira, apresentava através de artigos, os cuidados essenciais de higiene para prevenção de doenças. A segunda, orientava como utilizar animais em aulas observatórias, devendo 0 estudante visualizar e registrar suas características morfológicas, hábitos de vida e utilidade para 0 homem. E as últimas três, sequências uma da outra, descreviam minuciosamente como desenvolver experimentações em sala de aula.

Outras duas seções, "Exercícios para todos os graus" e "Educação Pré-primária", também apresentavam atividades vinculadas a essa área do conhecimento, embora o foco não fosse 0 Ensino de Ciências. Ademais, encontraram-se suplementos, planos de aula, unidades didáticas, versos, informativos, gravuras explicativas e artigos científicos.

Dentre as metodologias utilizadas, constatou-se expressividade na experimentação, presente em mais de $87 \%$ dos exemplares do período, emergindo a seguinte questão problema: "Como eram abordadas as propostas didáticas de experimentações no Ensino de Ciências, contidas na Revista do Ensino do Rio Grande do Sul no período de 1951 a 1961?".

Nesse período, o Ensino de Ciências era indicado a partir das disciplinas de Ciências Naturais" e "Higiene", presentes em apenas um dos anos do Primário; nas duas últimas séries do Ginasial, também intitulada como "Ciências Naturais"; e no nível Colegial, subdivisão em Química, Física e História Natural (Biologia), conforme estabelecido pelas Leis Orgânicas de 1942 e 1946 (MAGALHÃES JÚNIOR; PIETROCOLA; ORTÊNCIO FILHO, 2011).

Somente a partir da promulgação da Lei n. 4.024, que fixou as Diretrizes e Bases da Educação Nacional (BRASIL, 1961), é que 0 Ensino de Ciências passou a ser exigido legalmente nos quatro anos do Ginasial. Por esse motivo, optou-se em estabelecer como recorte temporal da pesquisa a data inicial da segunda fase de distribuição da Revista (1951) até a promulgação dessa Lei (1961). 
De acordo com Krasilchik (2000), a década de 1950 pode ser caracterizada como um período de transição, onde foram intensificadas as ideias de mudar o método expositivo para ativo. Beltran (2015), ao pesquisar a história da Ciência e do ensino no laboratório, atribui duas linhas para experimentação nesse período, baseadas nas tendências de ensino tradicional e renovado. Na primeira, o professor é protagonista do experimento e, a ação discente restrita a observação e realização de exercícios práticos; na segunda, prega-se que 0 estudante deve pensar como cientista e, portanto, aprender fazendo.

0 interesse nas experimentações também se justifica devido sua relevância no processo de ensino e aprendizagem de Ciências, pois essa metodologia, quando empregada de forma contextualizada, problematizada e com objetivos bem definidos, pode contribuir para emancipação do pensamento científico (DELIZOICOV, 1991). Dentre suas vantagens, pode-se destacar: autonomia na formulação de hipóteses; construção de ideias entre os pares; desenvolvimento argumentativo; e melhoria nas interações intelectuais, físicas e sociais (OLIVEIRA, 2010; FRANCISCO JUNIOR et al., 2008; GALIAZZI, M. C. et al., 2001).

Com base no exposto, estabeleceu-se como objetivos: analisar as propostas didáticas de experimentações das seções "Observando plantas", "Observando" e "Observações e Experiências" da RE/RS no período supracitado, a predominância disciplinar e os conteúdos científicos abordados pelas mesmas. Para tanto, os dados empíricos foram obtidos nos exemplares disponíveis no Repositório Digital Tatu $(\mathrm{RDT})^{5}$, vinculado a Universidade Federal do Pampa - UNIPAMPA, sendo a abordagem técnico-metodológica pautada na Análise Documental.

\section{CAMINHOS DA PESQUISA}

Metodologicamente classifica-se quanto a natureza como qualitativa, caracterizada por Denzin e Lincoln (2006) como aquela que busca a interpretação de fenômenos da realidade social e o significado que as pessoas e as fontes Ihe conferem. Segundo Gil (2002, p. 134), neste tipo de pesquisa, "[...] o conjunto inicial de categorias em geral é reexaminado e modificado sucessivamente, com vista em obter ideias mais abrangentes e significativas", considerando aspectos que possam enriquecer os resultados encontrados, tais como, narrativas, imagens, símbolos e esquemas.

No que se refere aos procedimentos, trata-se de uma pesquisa documental, pois considera como fonte registros que ainda não receberam tratamento analítico: "[...] documentos, escritos ou não, constituindo o que se denomina de fontes primárias" (MARCONI; LAKATOS, 2010, p. 158); "[...] documentos, contemporâneos ou retrospectivos, considerados cientificamente autênticos (não fraudados)" (PÁDUA, 1997, p. 62). A palavra "documentos", entendida de forma ampla, inclui materiais escritos (jornais, revistas, memorandos, cartas, relatórios, diários, entre outros) e iconográficos (fotos, filmes, imagens e etc.) (GODOY, 1995).

Dentre as vantagens da utilização da pesquisa documental, Gil (2008) destaca as seguintes: (I) acesso ao passado a partir de documentos que constituem uma fonte estável de dados, (II) evidência dos processos de mudança social e cultural (III) e obtenção de dados com menor custo e sem constrangimento aos sujeitos.

No caso deste estudo, as fontes foram os exemplares da RE/RS, publicados no período de 1951 a 1961, disponíveis no RDT, vinculado a UNIPAMPA. Esse repositório inventaria fontes de pesquisa relacionadas à história da educação, compondo um acervo digital acessível e gratuito, com centenas

5 UNIPAMPA. Repositório Digital Tatu. Unipampa: Bagé, 2021. Disponível em: http://sistemas.bage.unipampa.edu.br/tatu/. Acesso em: 06 abr. 2021. 
de obras que incluem livros, cartilhas, revistas e produções acadêmicas, que podem servir de suporte aos pesquisadores de diversas áreas do conhecimento (BICA; RODRIGUES; GERVÁSIO, 2019).

Neste sentido, acredita-se ser coerente 0 emprego da Análise Documental como abordagem técnico-metodológica, descrita por Cunha (1989) como um conjunto de procedimentos que buscam expressar o conteúdo dos documentos, vislumbrando formas que facilitem sua recuperação. Consiste em três etapas primordiais (analisar, sintetizar e representar), que podem ser obtidas com auxílio da classificação, indexação e elaboração de resumos (BICA, 2013).

A primeira etapa, análise, é elucidada por Pimentel (2001) como um processo de "garimpagem". As categorias emergem a partir do contato de idas e vindas do pesquisador com as fontes, como num garimpo, norteado pela questão de pesquisa. Conforme corrobora Lopes e Galvão (2001), algumas podem ser definidas a priori, enquanto outras emergem somente com a revisão minuciosa e detalhada das fontes.

Desse modo, com o intuito de criar familiaridade com os documentos, inicialmente realizou-se a leitura flutuante das edições, etapa fundamental para conhecer o conteúdo geral da RE/RS. Na segunda leitura, mais pontual, foram salvas as páginas que possuíam relação direta ou indireta com 0 Ensino de Ciências, informações sintetizadas em quadros, que possibilitaram identificar que as seções "Observando plantas", "Observando" e "Observações e Experiências" apresentavam-se em maior quantidade nesta área do conhecimento, motivo da escolha. A análise das propostas didáticas de experimentações foi desenvolvida em duas categorias, descritas no Quadro 1.

Quadro 1 - Categorias analisadas na pesquisa.

\begin{tabular}{|c|c|l|}
\hline Categoria Primária & Categorias Secundárias & \multicolumn{1}{|c|}{ Descrição } \\
\hline \multirow{4}{*}{ Análise por edição } & Aspectos gerais & $\begin{array}{l}\text { Descreve o quantitativo de exemplares que contém as seções } \\
\text { analisadas e o número de experimentações em cada uma. }\end{array}$ \\
\cline { 2 - 3 } & Predominância & $\begin{array}{l}\text { Classifica as experimentações de cada seção em monodisciplinar } \\
\text { (destinadas a Biologia, Física ou Química) ou multidisciplinar } \\
\text { (compilados que abrangem mais de uma componente). }\end{array}$ \\
\cline { 2 - 3 } & Relações entre as componentes & $\begin{array}{l}\text { Verifica se as experimentações dos compilados são aleatórias ou } \\
\text { possuem relação entre si. }\end{array}$ \\
\hline \multirow{2}{*}{$\begin{array}{c}\text { Análise por proposta didática } \\
\text { de experimentação }\end{array}$} & $\begin{array}{l}\text { Classifica, individualmente, a predominância disciplinar das } \\
\text { experimentações. }\end{array}$ \\
\cline { 2 - 3 } & Conteúdos científicos & $\begin{array}{l}\text { Identifica o conteúdo geral e específico abordado em cada } \\
\text { experimentação. }\end{array}$ \\
\cline { 2 - 3 } & $\begin{array}{l}\text { Contextualização e } \\
\text { questão problema }\end{array}$ & $\begin{array}{l}\text { Verifica se as experimentações são contextualizadas e/ou } \\
\text { apresentam questão problema. }\end{array}$ \\
\hline
\end{tabular}

Fonte: Elaborado pelos autores.

Salienta-se que a separação didática em Biologia, Física e Química é apenas para fins de estudo, os fenômenos e a natureza apresentam-se de forma plural, um rizoma que conecta todas áreas do conhecimento. Por esse motivo, a categorização por componente curricular pautou-se nos seguintes critérios: (1) Biologia: experimentações que englobam os seres vivos, suas características e relações entre si e 0 ambiente; (2) Física: experimentações que dizem respeito às leis do universo e suas interações; (3) Química: experimentações que abordam reações químicas, composição e propriedades da matéria. 
Neste sentido, para auxiliar na obtenção dos dados, organizou-se um inventário, ferramenta que consiste em descrever (alguma coisa) com riqueza de detalhes. A exemplo, 0 Quadro 2 mostra a análise de um dos experimentos da edição de Abril de 1954.

Quadro 2 - Modelo utilizado para inventariar as propostas didáticas de experimentações da RE/RS.

\begin{tabular}{|c|c|}
\hline Número do item & 24 \\
\hline Identificação & RE/RS (a. III, n. 21, abril, 1954, p. 29). \\
\hline Seção & Observações e Experiências \\
\hline Título & Tropismo \\
\hline Transcrição & $\begin{array}{l}\text { "Geotropismo - deixando o feijoeiro crescer no vaso com terra durante uns } 20 \text { dias, procura-se inverter o vaso, } \\
\text { conservando suspenso por arames ou barbante, tendo sempre o cuidado de regalo } 4 \text { a } 5 \text { vezes por dia. Ao cabo } \\
\text { de uma semana já poderemos notar que o caulículo em curva para cima, e retirada a planta da terra observa- } \\
\text { remos que a raiz também se encurvou dirigindo-se para baixo; a experiência prova que no vegetal a raiz tem } \\
\text { geotropismo positivo e o caule, negativo; em outras palavras, um cresce para baixo, outro para cima". }\end{array}$ \\
\hline Contextualização & Ausente \\
\hline Problematização & Ausente \\
\hline \multicolumn{2}{|l|}{ Ilustração } \\
\hline Predominância & $\begin{array}{l}\text { (X) Biologia } \\
\text { ( ) Física } \\
\text { ( ) Química }\end{array}$ \\
\hline Conteúdo principal & Botânica \\
\hline Conteúdo específico & Tropismo: geotropismo. \\
\hline Público-alvo & $\begin{array}{l}\text { ( ) Pré-primário } \\
\text { ( ) Primário. Ano? } \\
\text { () Ginasial. Série? } \\
\text { (X) Não descrito }\end{array}$ \\
\hline
\end{tabular}

Fonte: Elaborado pelos autores.

A seguir apresenta-se a síntese e a representação dos resultados, etapas pautadas na interpretação e inferência dos pesquisadores a partir dos dados obtidos.

\section{A EXPERIMENTAÇÃO NA REVISTA DO ENSINO}

No período delimitado neste estudo (1951-1961) foram publicados 80 exemplares da RE/RS, sendo 45 disponíveis para consulta no RTD, conforme Quadro 3. 0 quantitativo corresponde a 56\% 
do total de publicações do recorte temporal, que na época, era distribuída em dois ciclos anuais: de março a junho e de agosto a novembro, respectivamente (RE/RS, a. VIII, n. 58, maio, 1952). Nos meses de férias escolares (janeiro, fevereiro, julho e dezembro) a revista entrava em recesso.

Quadro 3 - Edições da Revista do Ensino do Rio Grande do Sul analisadas (1951-1961).

\begin{tabular}{|c|c|c|c|c|c|c|c|c|c|c|c|c|c|}
\hline \multirow{3}{*}{$\begin{array}{c}\text { Ano de } \\
\text { publicação }\end{array}$} & \multicolumn{13}{|c|}{ Edições mensais disponíveis para análise } \\
\hline & \multicolumn{2}{|c|}{ Recesso (R) } & \multicolumn{4}{|c|}{$1^{0}$ Ciclo anual de distribuição } & \multirow{2}{*}{$\begin{array}{c}\text { (R) } \\
\dot{\Xi}\end{array}$} & \multicolumn{4}{|c|}{$2^{\circ}$ Ciclo anual de distribuição } & \multirow{2}{*}{$\begin{array}{l}\text { (R) } \\
\text { ป̊ }\end{array}$} & \multirow[b]{2}{*}{ Total } \\
\hline & 灾 & ฮัँ & 离 & 这 & $\frac{\text { 음 }}{\stackrel{N}{E}}$ & 竞 & & 安 & ळ. & 㝋 & oे & & \\
\hline 1951 & & & & & & & & & & & $\mathrm{x}$ & & 01 \\
\hline 1952 & & & $\mathrm{x}$ & $\mathrm{x}$ & $\mathrm{X}$ & & & $\mathrm{x}$ & & & & & 04 \\
\hline 1953 & & & $x$ & & & & & & $\mathrm{x}$ & & & & 02 \\
\hline 1954 & & & $x$ & $\mathrm{x}$ & $\mathrm{x}$ & $\mathrm{x}$ & & & & $\mathrm{x}$ & & & 05 \\
\hline 1955 & & & $x$ & & & $x$ & & $x$ & & $X^{2}$ & & & 04 \\
\hline 1956 & & & & & & & & & & $x$ & & & 01 \\
\hline 1957 & & & $x$ & & $\mathrm{x}$ & & & $\mathrm{x}$ & $\mathrm{x}$ & $x$ & $\mathrm{x}$ & & 06 \\
\hline 1958 & & & $\mathrm{x}$ & & $X^{1}$ & & & & $\mathrm{x}$ & $\mathrm{x}$ & $\mathrm{x}$ & & 05 \\
\hline 1959 & & & $x^{3}$ & $\mathrm{x}$ & & $\mathrm{x}$ & & $x$ & $x$ & $x$ & $X^{3}$ & & 07 \\
\hline 1960 & & & $\mathrm{x}$ & $X^{1}$ & $\mathrm{x}$ & & & $X^{1}$ & & $X^{1}$ & & & 05 \\
\hline 1961 & & & & $x$ & $\mathrm{X}^{1}$ & & & $\mathrm{x}$ & & $x$ & $\mathrm{x}$ & & 05 \\
\hline
\end{tabular}

Legenda: $X$ - edições analisadas; $X^{1}$ - exemplares analisados que não possuem as seções delimitadas;

$X^{2}$ - possui uma das seções no sumário, mas a página está indisponível para análise; $X^{3}$ - não foi possível aferir se há ou não as seções delimitadas.

Fonte: Elaborado pelos autores.

Constatou-se que 37 exemplares (82\%) possuíam as seções analisadas. "Observando Plantas" foi 0 título dado à publicação de novembro de 1951, que apresentava três propostas destinadas ao estudo das plantas. A partir da edição seguinte até o final de 1952, a denominação mudou para "Observando...", pois não se restringia somente ao conteúdo de botânica. Encontraram-se propostas de Física (temperatura, eletricidade, posicionamento e alavancas), Química (densidade da água) e Biologia (relações interespecíficas). Em 1953, o nome mudou novamente para "Observações e Experiências", porém, continuou com o mesmo objetivo, motivo pelo qual, na apresentação dos resultados não haverá distinção entre as seções.

Nos outros oito exemplares (18\%), não foi possível analisar as propostas didáticas de experimentações. A edição de outubro de 1955 (02\%) apresentava a seção no sumário, mas a página estava indisponível para consulta. Março e novembro de 1959 (05\%) possuíam ausência de páginas, impossibilitando a aferição. E maio de 1958, abril, agosto e outubro de 1960 e maio de 1961 (11\%), não possuíam seções destinadas ao Ensino de Ciências, demarcando que a experimentação era um elemento presente na revista.

De acordo com Bastos (2005) poucas seções mantiveram-se por vários anos na RE/RS, sendo "Observações e Experiências" uma delas. Juntamente com as duas anteriores delimitadas neste 
estudo, descrevem minuciosamente como desenvolver em sala de aula propostas didáticas de experimentações no Ensino de Ciências.

Quanto à predominância, 26 edições $(70 \%)$ apresentam experimentos monodisciplinares: Biologia (46\%), Física (10\%) e Química (14\%). As demais edições (11) possuíam compilados com propostas que abordavam mais de uma componente: Biologia e Física (11\%), Biologia e Química (3\%), Física e Química (11\%) e Biologia, Física e Química (5\%), total 30\%. Em três delas, as experimentações relacionavam-se entorno de uma temática, conforme exemplificado a seguir, e as outras oito, traziam experimentos aleatórios.

A publicação de Março de 1955, dispõe oito experimentos que perpassam as componentes de Biologia e Química, interligados pela temática da água. Em Biologia, propunha observar diferentes amostras d'água e a respiração dos organismos aquáticos; em Química, mudanças dos estados físicos da matéria (fusão, solidificação, vaporação e sublimação) e separação de misturas (filtração e destilação).

Semelhante, três dos seis experimentos da edição de Outubro de 1956 eram sobre 0 solo. 0 primeiro identifica a acidez, visualizada pela coloração do papel tornassol. 0 segundo, estimula a plantação de leguminosas para posterior análise do desenvolvimento. E 0 terceiro, contextualiza a aplicação dos elementos químicos Fósforo, Potássio, Nitrogênio e Cálcio como adubos, orientando a importância para as plantas e a quantidade adequada. Para tanto, sugere a construção de quatro canteiros uniformemente adubados com os respectivos elementos e combinação entre eles.

Já, em Março de 1958, três experimentações são relacionadas à respiração. Na primeira, os estudantes devem observar: 0 número médio de movimentos respiratórios por minuto, 0 caminho percorrido pelo ar e a forma correta de respirar. Na experimentação seguinte, perceberão que: há mudanças de temperatura entre 0 ar expirado pelo nariz e pela boca, a temperatura corporal é superior à do ambiente e a expiração desprende vapor d'água. E na última, constituição do sistema respiratório, sugere a construção de um pulmão de copo. Nesta, apresenta a seguinte questão norteadora: "0 aumento e diminuição de volume dos pulmões serão o resultado da entrada e saída do ar? Ou será que a entrada e saída do ar são consequências do trabalho de alguns músculos?" (RE/RS, a. VII, n. 50, março, 1958, p. 9). A Figura 1, mostra a estrutura do pulmão de copo, semelhante ao confeccionado com garrafa pet atualmente.

Figura 1 - Esquema para construção do pulmão de copo, proposto pela RE/RS.

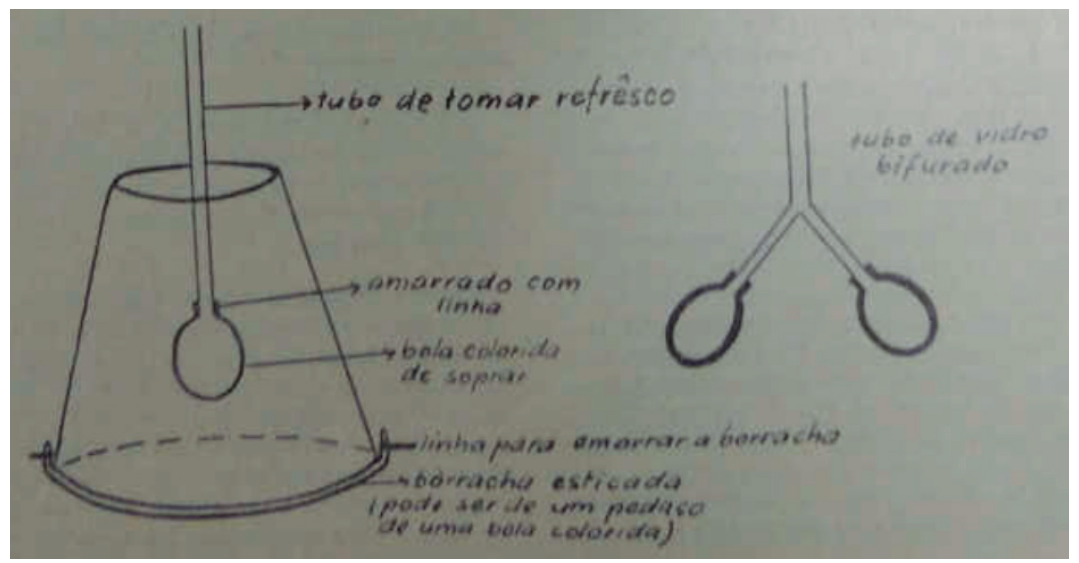

Fonte: Revista do Ensino (a. VII, n. 50, março, 1958, p. 9). 
Salienta-se que, se aplicadas juntas, essas experimentações abarcam as três componentes das Ciências da Natureza, são exemplos: Biologia, evidenciada pela estrutura e composição do sistema respiratório; Física, mudanças de temperatura e movimento; Química, ao abordar que 0 ar expirado é composto por partículas de água, que quando aquecidas alteram seu estado físico, transformando-se em vapor (mudanças de estados físicos).

Constata-se, portanto, que as três edições até aqui mencionadas, apresentam vestígios de interdisciplinaridade, ainda que não ocorressem debates sobre a temática no Brasil. As discussões no país iniciaram na década de 1960, principalmente, pelas pesquisas de Japiassú. 0 autor caracteriza a interdisciplinaridade como a troca de conhecimento entre especialistas e a interação das disciplinas, sinalizando-a como organização curricular (JAPIASSÚ, 1976).

Já Fazenda (2012), numa concepção contemporânea, conceitua a interdisciplinaridade como postura de atitude e ousadia perante as ações desenvolvidas no ensino. Considera os aspectos da realidade humana e estimula a criação de situações-problema. Desse modo, essas experimentações temáticas (água, solo e respiração), ainda que incipientes, possibilitavam a interação entre as componentes, principalmente a última, que parte de uma questão-problema.

Em consonância, a publicação de Outubro de 1959, intitulada "Como utilizar as experiências no ensino elementar de Ciências", autoria do prof. Newton Dias dos Santos, orienta que "[...] as experiências não devem ser efetuadas com o propósito de demonstrar determinado assunto dado". Mas sim, "[...] tornar-se a espinha dorsal em torno da qual os conhecimentos são canalizados, podendo, desta maneira, levar 0 aluno a redescoberta" (RE/RS, a. IX, n. 64, outubro, 1959, p. 16-17). 0 autor defende que 0 assunto não deve ser abruptamente apresentado pelo docente, mas contextualizado e direcionado por situações-problemas. Para tanto, detalha minuciosamente, através da experimentação "pulmão de copo", apresentada na edição de Março de 1958, como realizar tal procedimento.

Ressalta-se que não há evidências científicas, e nem é propósito deste estudo, se os professores de Ciências planejavam e aplicavam as propostas como descrito pela revista. Inclusive, 0 quantitativo de edições que apresentavam um ou mais experimentos com contextualização e/ou problematização era baixo, total de cinco (14\%). Apesar disso, os indícios mostram que a orientação de contextualizar e problematizar as experimentações no Ensino de Ciências se fazia presente na década de 1950, através da RE/RS.

Autores como Delizoicov (1991), Rosito (2008) e Galiazzi et al. (2001) também defendem a problematização e a contextualização. E acrescentam a importância das experimentações serem utilizadas com fins definidos, guiadas pelos objetivos do professor, possibilitando o levantamento de hipóteses, o planejamento e a discussão acerca dos fenômenos. No entanto, estudos como 0 de Salvadego, Laburú e Barros (2009) sugerem que atualmente poucos professores conseguem articulá-las dessa maneira.

As demais experimentações da revista (86\%), se detinham a descrever detalhadamente os materiais e sua execução. A professora deveria conduzir a classe, passo a passo, para o caminho da redescoberta, tendo o método científico como condutor da resolução dos problemas (RE/RS, a. IX, n. 64, outubro, 1959). A busca pela verdade, aspecto da Ciência Moderna, interliga-se ao significado da palavra experimento: "[...] ensaio científico destinado à verificação de um fenômeno físico", ou seja, "[...] pôr à prova, ensaiar, testar" (ROSITO, 2008, p. 196). 
Percebe-se, portanto, predominância da concepção empirista, na qual, prega-se que 0 conhecimento provém unicamente da experiência que o meio físico (objeto) transmite ao ser (sujeito), um conhecimento que vem de fora para dentro (LIMA, 2016). Dentre as características deste tipo de experimentação, Deustch (1997) pontua: registros sistemáticos, replicabilidade e, mormente, foco na observação (DEUSTCH, 1997 apud LIMA, 2016).

Como exemplo, a edição de Novembro de 1951, orienta a semeadura da mesma espécie, em vasos e qualidade de terra iguais. Se cuidados da mesma maneira, os estudantes observarão que as plantas terão desenvolvimento semelhante. Logo tenham crescido, uma deve ser instalada em local arejado, com luminosidade adequada e regada diariamente. E a outra, colocada em lugar frio, sem luz solar e sem receber água, conforme ilustrado na Figura 2.

Figura 2 - Ilustração da Experimentação denominada Luz e Calor, contida na RE/RS.

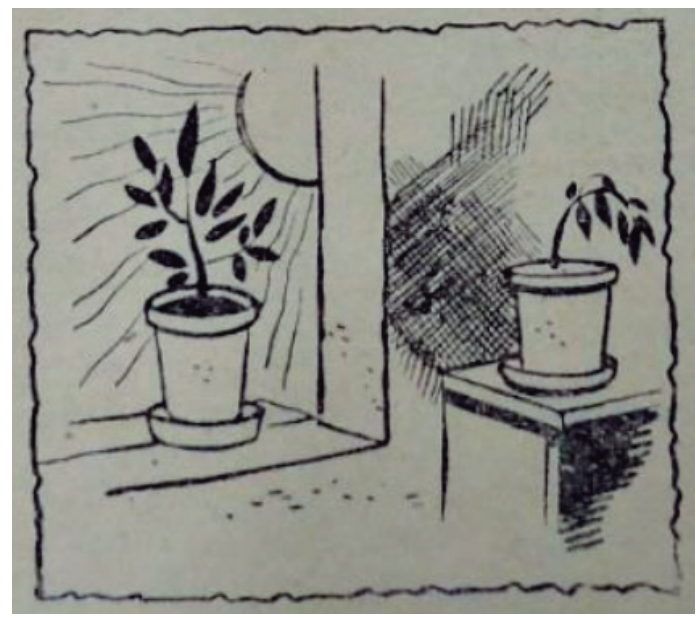

Fonte: Revista do Ensino (a. I, n.3, nov., 1951, p. 17).

Desse modo, a revista enunciava que "[...] as crianças logo notarão as consequências da diferença de tratamento e compreenderão a necessidade que as plantas têm de água, ar, luz e calor" (RE/RS, a. I, n.3, nov., 1951, p. 17), ou seja, conclusões obtidas pela observação e comparação. À propósito, também pode ser replicada e dispor de registros, demarcando o empirismo.

Para exemplificar as possibilidades da utilização dessas experimentações, na etapa seguinte, foram categorizadas indicando os possíveis conteúdos científicos a serem desenvolvidos em sala de aula. 0 Quadro 4, mostra 0 quantitativo de experimentações encontradas em cada edição, variabilidade entre zero e oito, média aritmética de 2,66 por exemplar e total de 120 aferições. A expressividade de experimentações inviabiliza uma discussão pormenorizada de cada uma delas, motivo pelo qual, neste artigo, optou-se em apresentar exemplos dos conteúdos mais recorrentes, que mostram as características comuns das propostas didáticas da época. 
Quadro 4 - Quantitativo de propostas didáticas de experimentações por edição analisada.

\begin{tabular}{|c|c|c|c|c|c|c|c|c|c|c|c|c|c|}
\hline \multirow{3}{*}{$\begin{array}{c}\text { Ano de } \\
\text { publicação }\end{array}$} & \multicolumn{13}{|c|}{ Edições mensais disponíveis para análise } \\
\hline & \multicolumn{2}{|c|}{ Recesso (R) } & \multicolumn{4}{|c|}{$1^{0}$ Ciclo anual de distribuição } & \multirow{2}{*}{$\frac{\text { (R) }}{\dot{5}}$} & \multicolumn{4}{|c|}{$2^{\circ}$ Ciclo anual de distribuição } & \multirow{2}{*}{ 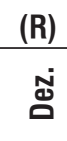 } & \multirow[b]{2}{*}{ Total } \\
\hline & 宛 & वें & 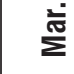 & 这 & 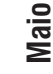 & 吾 & & 晏 & $\dot{\Phi}$ & 亏े & oे & & \\
\hline 1951 & & & & & & & & & & & 03 & & 03 \\
\hline 1952 & & & 03 & 03 & 04 & & & 02 & & & & & 12 \\
\hline 1953 & & & 03 & & & & & & 02 & & & & 05 \\
\hline 1954 & & & 03 & 03 & 05 & 06 & & & & 05 & & & 22 \\
\hline 1955 & & & 08 & & & 04 & & 03 & & 00 & & & 15 \\
\hline 1956 & & & & & & & & & & 06 & & & 06 \\
\hline 1957 & & & 06 & & 01 & & & 02 & 01 & 01 & 03 & & 14 \\
\hline 1958 & & & 03 & & 00 & & & & 02 & 01 & 04 & & 10 \\
\hline 1959 & & & 00 & 03 & & 02 & & 04 & 02 & 01 & 00 & & 12 \\
\hline 1960 & & & 02 & 00 & 05 & & & 00 & & 00 & & & 07 \\
\hline 1961 & & & & 05 & 00 & & & 03 & & 03 & 03 & & 14 \\
\hline
\end{tabular}

Fonte: Elaborado pelos autores.

Identificou-se que 56 (47\%) destinam-se a conteúdos da componente curricular de Biologia, predominância em Botânica (30) e Zoologia (15). Destaca-se ainda, que uma experimentação aborda os dois ramos simultaneamente, pois ensina como conservar plantas e animais em meio líquido (RE/RS, a. VII, n. 49, novembro, 1957). As outras propostas (20), referem-se à água (02), ar (01), corpo humano (03) e solo (04), conforme Quadro 5.

Quadro 5 - Classificação das experimentações da RE/RS por conteúdos relacionados a Biologia.

\begin{tabular}{|c|l|c|}
\hline Conteúdo & \multicolumn{1}{|c|}{ Conteúdo Específico } & Quantidade \\
\hline Água & Ciclo (01) e características (01). & $02 / 56$ \\
\hline Ar & Variação atmosférica (01). & $01 / 56$ \\
\hline Botânica & $\begin{array}{l}\text { Clorofila (02), germinação (08), herbário (01), leguminosas (01), luz e calor (04), morfologia (03), } \\
\text { plantas aquáticas (01), raiz (01) respiração (03), seiva (01), transpiração (02) e tropismo (03). }\end{array}$ & $30 / 56$ \\
\hline Corpo Humano & Sistema respiratório (03) & $03 / 56$ \\
\hline Solo & Acidez (01), plantação (01), rochas (01) e tipos (01). & $04 / 56$ \\
\hline Zoologia & $\begin{array}{l}\text { Anfíbios (03), artrópodes (02), empalhamento (01), moluscos (01), peixes (04), preparação de } \\
\text { esqueletos (01), respiração de organismos aquáticos (01), relações interespecíficas (02). }\end{array}$ & $15 / 56$ \\
\hline Zoologia e Botânica & Conservação em meio líquido (01). & $01 / 56$ \\
\hline
\end{tabular}

Fonte: Elaborado pelos autores.

0 conteúdo de Zoologia se sobressaiu nas edições de 1957, com abordagens temáticas sobre 0 uso didático do aquário (março, agosto e setembro) e criação do museu inanimado (outubro e novembro). Apresentava excertos do livro "Práticas de Ciências: Guia do Ensino Elementar", autoria do já citado Prof. Newton dos Santos (SANTOS, 1957), indicativo que o profissional colaborou com frequência na RE/RS. 
0 exemplar de Março, mostra possibilidades da criação de peixes e girinos em aquários: com os osteíctes, orienta a observação da locomoção, respiração, reação e captura de alimentos; com os anuros, a locomoção e metamorfose dos girinos (RE/RS, a. VI, n. 42, março, 1957). Em Agosto, foca-se na classe gastropoda, pois contextualiza os dois tipos mais comuns de caramujos que podem ser cultivados em aquários, seus habitats, distribuição geográfica no Brasil, a doença que um deles pode transmitir e o gênero pertencente (RE/RS, a. VI, n. 46, agosto, 1957). E, Setembro, apresenta alguns insetos cultivados em aquários, tais como, baratinhas d’água, larvas de mosquitos e libélulas. Destaca os habitats para captura e propõe explorar o período de sobrevivência no aquário, alimentação e morfologia. (RE/RS, a. VII, n. 47, setembro, 1957).

Referente ao museu inanimado, as experimentações de Outubro demonstram como coletar, abater, preparar, conservar e classificar os insetos para compor um entomóforo. Na fase de coleta ensina a confeccionar redes de captura, utilizando arame, madeira e saco de filó. De acordo com a periculosidade que oferecem, orienta como apanhar e matar os insetos já capturados na rede, com 0 intuito de não danificar a estrutura. Mostra a preparação e os produtos químicos indicados (éter, por exemplo) para conservação. E apresenta diversas sugestões para 0 agrupamento dos insetos, que podem ser classificados quanto a morfologia, classe, ordem, etc. Por último, sugere que "[...] a turma, orientada pela professora deve estudar os insetos que vivem no horto e nas imediações da escola, colecionando-os, montando-os, anotando os seus hábitos e organizando um relatório ilustrado". (RE/RS, a. VII, n. 48, outubro, 1957, p. 10).

Na publicação do mês seguinte, apresenta-se vantagens e desvantagens da conservação em meio líquido, abordagem de zoologia e botânica, pois cita exemplos de animais e vegetais que só podem ser mantidos nesse meio. Orienta possíveis formas de abatê-los (asfixia ou embebidos em éter), a natureza do líquido conservador (teor do álcool indicado para animais contráteis e não contráteis) e os tipos de frascos nos quais podem ser armazenados (RE/RS, a. VII, n. 49, novembro, 1957). Na sequência, descreve como obter peças ósseas, através da preparação, cozimento da carcaça, clareamento e montagem dos ossos, conforme descrito a seguir:

[...] Para o preparo dos ossos podemos proceder da seguinte maneira: Obtenção da peça - pode-se recorrer a um animal morto acidentalmente, abatido a tiro, em armadiIha ou simplesmente comprando [...] Preparação da carcaça - [...] escalpado 0 animal, pratica-se uma ampla incisão na linha mediana da face ventral do abdômen e retiram-se todas as vísceras abdominais e torácicas, sobrando apenas a carcaça osteomuscular. Cozimento da carcaça - [...] ferve-se a mesma em água, melhor ainda em água bicabornatada, até o cozimento completo, de maneira que permita destacar facilmente a carne dos ossos, por meio de pinças e canivete. [...] torna-se a cozinhar a carcaça a fim de retirar todos os resíduos de tecido que ainda se encontrarem aderentes. Durante essas operações, os ossos desligarão as articulações devendo-se ter cuidado de anotar a sua posição caso se queira executar uma montagem total. Clareamento dos ossos - [...] mergulhar numa mistura de água oxigenada durante algumas horas e no escuro. Retirar após algumas horas e secar ao sol até ficarem brancos. Montagem numa prancha de cartolina, papelão ou madeira, fixe os ossos, por partes: na linha mediana: a cabeça, a coluna vertebral e a bacia; nos lados paralelamente: os membros superiores e os membros inferiores. Podemos montar ossos homólogos de vários animais para ilustrar (RE/RS, a. VII, n. 49, novembro, 1957, p. 9-10, grifos nossos). 
Por fim, ensina técnicas de empalhamento de vertebrados, detalhando a retirada e envenenamento da pele, enchimento, montagem simples e secagem. A Figura 3 ilustra, passo a passo, 0 procedimento da retirada de pele de um rato: (1) incisão ventral entre 0 externo e 0 púbis, descolamento da pele com 0 auxílio de uma pinça e de uma espátula, (2) posição para retirar a pele da coxa, empurrando-a em direção ao corte, (3) descolamento da pele da cauda com o auxílio da mão direita e de uma pinça, que puxa em sentido contrário, (4) retirada da pele em torno da cabeça, virando-a do avesso, como quem despe uma camiseta.

Figura 3 - Ilustração da retirada da pele de animais, etapa do empalhamento, contida na RE/RS.

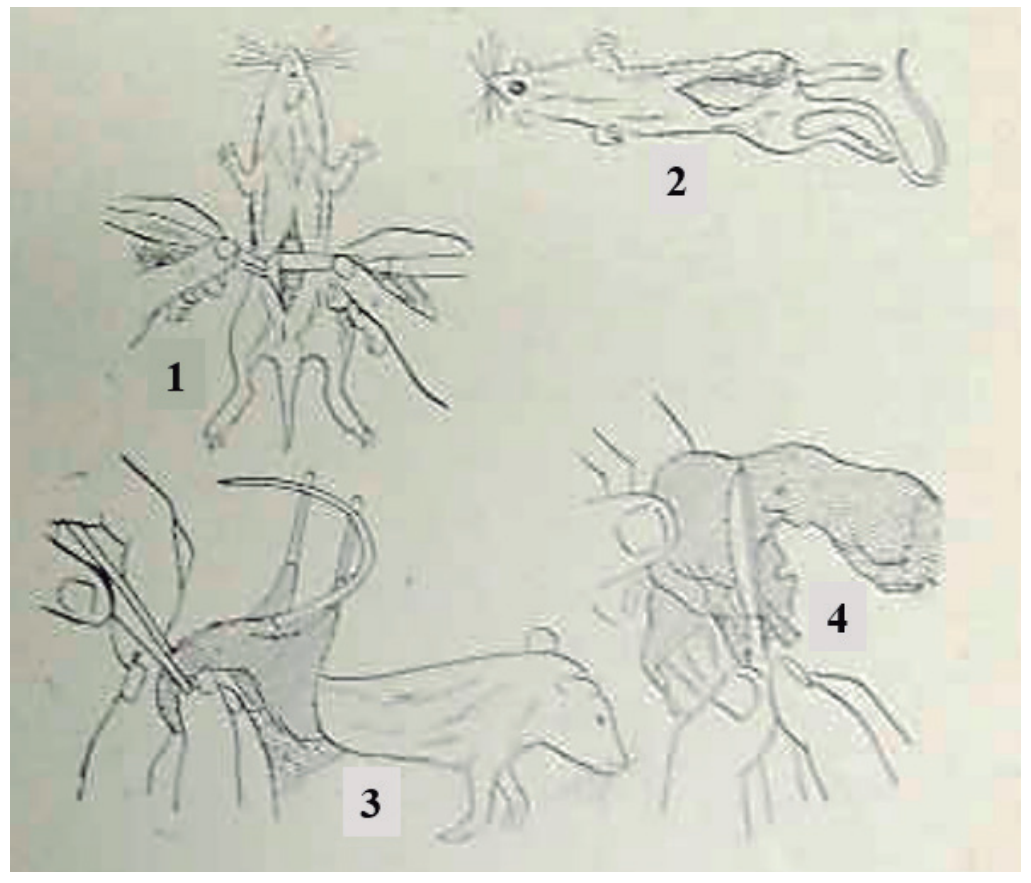

Fonte: Adaptado da Revista do Ensino (a. VII, n. 49, nov., 1957, p. 11).

Percebeu-se que essas propostas, destacam-se pela riqueza de detalhes e aporte de imagens para execução, possibilitando ao professor montar coleções e peças que auxiliem na compreensão das características de alguns filos do reino animália, principalmente, arthropodas e chordatas. Se utilizadas com fins didáticos, constituíam coleções zoológicas, importante instrumento que possibilita a observação e manuseio de espécies devidamente preservadas, evidenciando suas características e diferenças (MARTINS, 1994; SILVA, CORRÊA, MATOS, 2014).

Ainda se tratando de coleções, em Setembro de 1961, propõe-se confeccionar um quadro ou álbum com folhas de vegetais. Para tanto, os estudantes devem colher amostras das plantas mais comuns na localidade, armazená-las com papel jornal prensado por uma lâmina de madeira, de modo que, não enrugam ao secar. A troca do papel deve ser diária, impedindo que mofem e, para facilitar a secagem, convém que se façam círculos na madeira. Após secas, "[...] as folhas são presas em cartolina ou caderno de desenho com fita colante, escrevendo-se, ao lado, o nome vulgar do vegetal a que pertencem. Isto constituirá uma coleção de folhas das plantas mais comuns na localidade". (RE/RS, a. X, n. 78, setembro, 1961, p. 50). 
Identificou-se que essa experimentação era a única que estimulava a construção de um herbário: "[...] coleção de plantas ou partes delas, secas e armazenadas", que podem ser utilizadas para fins didáticos (FONSECA; VIEIRA, 2015, p. 07). A maioria das propostas de Botânica focavam na germinação (08). A exemplo, Março de 1954, apresentava a comumente experimentação do feijão no algodão. Os estudantes deveriam plantá-lo nesse material e numa lata com terra, tendo 0 cuidado de molhar de três a quatro vezes ao dia. Através de registros esporádicos, observariam que ambos germinam e que, ao término de algumas semanas, o que estava no algodão morre, pois esgota a reserva alimentar encontrada nos cotilédones (RE/RS, a. III, n. 20, março, 1954).

Utilizando esses mesmos materiais, uma proposta de Setembro de 1959, sugere que sejam colocados feijões plantados no algodão em dois lugares contrastantes: iluminado e arejado versus escuro e pouca ventilação. Com observações diárias, deve ser comparada a germinação (RE/RS, a. IX, n. 63, setembro, 1959). Complementar, Agosto de 1961, apresenta três experimentações que mostram os elementos indispensáveis para o desenvolvimento de uma planta: luz, ar e água. Nesta última, visualiza-se as sementes em potes com ausência e quantidade excessiva, insuficiente e adequada de água. (RE/RS, a. X, n. 77, agosto, 1961).

De modo geral, as experimentações desse campo da Biologia, não podiam ser desenvolvidas em uma única aula, pois requeriam observações e comparações diárias ou esporádicas. A intenção dos experimentos era revelar a teoria com elementos da natureza, reforçando o positivismo e o método científico.

No que se refere a Química, identificaram-se 34 propostas (28\%), com prevalência nos tópicos de Propriedades da Matéria (24) e Mudanças de Estados Físicos (07). Em menor proporção, Separação de Misturas (02) e Elementos químicos (01), conforme Quadro 6.

Quadro 6 - Classificação das experimentações da RE/RS por conteúdos relacionados a Química.

\begin{tabular}{|c|l|c|}
\hline Conteúdo & \multicolumn{1}{|c|}{ Conteúdo Específico } & Quantidade \\
\hline Elementos químicos & Elementos químicos utilizados em adubos (01) & $01 / 34$ \\
\hline $\begin{array}{c}\text { Mudanças de } \\
\text { Estados Físicos }\end{array}$ & $\begin{array}{l}\text { Fusão, vaporação e liquefação (01), fusão e sublimação (01) solidificação (01) e vaporação } \\
\text { (04). }\end{array}$ & $07 / 34$ \\
\hline $\begin{array}{c}\text { Propriedades da } \\
\text { Matéria }\end{array}$ & $\begin{array}{l}\text { Combustão (01), compressibilidade (01), compressibilidade e elasticidade (01), densidade } \\
\text { (03), divisibilidade (01), elasticidade (01), extensão (01), inércia (01), impenetrabilidade } \\
\text { (01), massa (04), porosidade (02), pressão (05), solubilidade (01) e volume (01). }\end{array}$ & $24 / 34$ \\
\hline Separação de Misturas & Filtração (01) e destilação (01) & $02 / 34$ \\
\hline
\end{tabular}

Fonte: Elaborado pelos autores.

As experimentações dessa componente, normalmente, eram apresentadas em compilados, elaborados com materiais acessíveis. Referente às Propriedades da Matéria, a compressibilidade e elasticidade eram demonstradas através de balões e seringas: "[...] encher de ar, soprando, uma dessas bolas coloridas, de borracha; apertar com os dedos - verificar a diminuição de volume (compressibilidade) e a volta ao volume inicial (elasticidade)"; "[...] tomar uma seringa de injeção - obturar, com polegar, o local de saída de ar - (onde se coloca agulha) e comprimir o êmbolo; verificar que este não atinge 0 outro extremo, e cessada a compreessão ele volta à posição inicial" (RE/RS, a. III, n. 23, junho, 1954, p. 29).

$\mathrm{Na}$ divisibilidade, orientava-se rasgar um pedaço de papel em partes cada vez menores ou transportar metade da água de um copo cheio para um vazio. A extensão, era observada pela porção 
de espaço que os objetos da classe (tinteiro, régua e folha) ocupavam. E a porosidade, explicada introduzindo alfinetes numa borracha, pois esta "[...] é formada de partículas muito pequenas, não visíveis a olho nu; quando 0 alfinete penetra, empurra estas partículas umas contra as outras, diminuindo os espaços entre elas existentes". (RE/RS, a. IV, n. 31, junho, 1955, p. 16).

Além dessas, também eram abordadas a densidade, impenetrabilidade, inércia, massa e volume, evidências que supõem que as propriedades gerais da matéria eram mais divulgadas que as específicas, representadas somente por duas experimentações referentes à solubilidade e à combustão. A primeira, orientava a relacionar os corpos solúveis em água a partir da adição de açúcar e sal (RE/RS, a. IV, n. 28, março, 1955) e na segunda, cobre-se uma vela acesa para comprovar que o gás absorvido é 0 oxigênio e que este é um elemento indispensável à combustão. (RE/RS, a. VIII, n. 61, junho, 1959, p. 19).

Por fim, as Mudanças de Estados Físicos foram representadas em todas as suas formas: fusão, vaporação, liquefação, solidificação e sublimação. De acordo com Alves (2013), a fusão consiste na passagem do estado sólido para o líquido e a solidificação é o processo inverso. A vaporação, ocorre em três formas distintas: evaporação, ebulição e calefação, passagem lenta, rápida e instantânea do líquido para gasoso, respectivamente, sendo o oposto, a liquefação. Já as mudanças sólido-gasoso denominam-se sublimação.

0 exemplar de Março de 1955, sugere a observação do derretimento do gelo (fusão), aquecimento da água (ebulição), encostar um prato ao vapor (liquefação) e levar o líquido recolhido ao congelador (solidificação) (RE/RS, a. IV, n. 28, março, 1955).

Já em Abril de 1959, três das sete experimentações tratam da evaporação: processo que consiste na passagem lenta e gradual do estado líquido para o gasoso. A primeira compara a evaporação do líquido de um pires e de um frasco de boca estreita, para mostrar que "[...] a evaporação é tanto maior quanto maior for a superfície" (p. 20). A segunda, utiliza dois recipientes iguais com a mesma quantidade de água, sendo um livre e outro coberto com um copo virado, concluindo que "[...] a evaporação da água é tanto mais rápida quanto mais seco é 0 ar" (p. 20). E a terceira, utiliza água quente e fria para mostrar que a primeira evapora mais rapidamente (RE/RS, a. VIII, n. 59, abril, 1959).

$\mathrm{Na}$ última componente analisada, Física, identificaram-se 30 experimentações (25\%), predominância nos ramos da Mecânica (10) e Termologia (10). As outras propostas (10), referem-se a: Acústica (04), Astronomia (01), Eletricidade (02), Meteorologia (02) e Ótica (01), conforme Quadro 7.

Quadro 7 - Classificação das experimentações da RE/RS por conteúdos relacionados a Física.

\begin{tabular}{|c|l|c|}
\hline Conteúdo & \multicolumn{1}{|c|}{ Conteúdo Específico } & Quantidade \\
\hline Acústica & Acústica (04) & $04 / 30$ \\
\hline Astronomia & Causas do dia e da noite (01) & $01 / 30$ \\
\hline Eletricidade & Eletromagnetismo (01) e utilidades para o homem (01) & $02 / 30$ \\
\hline Mecânica & $\begin{array}{l}\text { Alavancas (02), equilíbrio entre corpos (02), equilíbrio de forças (02), forças angulares (01), } \\
\text { força centrífuga (01), força gravitacional (01) e forças paralelas (01). }\end{array}$ & $10 / 30$ \\
\hline Meteorologia & Precipitação (01) e umidade atmosférica (01) & $02 / 30$ \\
\hline Ótica & Ilusão de ótica (01) & $01 / 30$ \\
\hline Termologia & Combustão (01), condutibilidade (01), dilatação (01), sensação térmica (01) e temperatura (06). & $10 / 30$ \\
\hline
\end{tabular}

Fonte: Elaborado pelos autores. 
Dentre os seis conteúdos específicos da Termologia, a Temperatura foi o mais abordado. Como exemplo, a experimentação de Março de 1952, intitulada "Como trabalha um termômetro", demonstra o funcionamento do equipamento, conforme excerto

Para que seus alunos entendam bem como trabalha um termômetro, faça em aula a seguinte demonstração: [...] Enche-se um frasco com água colorida, coloca-se a rolha anteriormente atravessada pelo tubo de vidro. Ao apertar a rolha, a água subirá alguns centímetros. Para demonstrar como termômetro trabalha sobre 0 efeito do calor, coloca-se 0 frasco dentro de uma vasilha com água fervendo (banho-maria). As crianças observarão a água colorida subir no tubo, tal como acontece ao mercúrio ou álcool contido no termômetro. Para baixar o líquido rapidamente, mergulhe 0 frasco na água fria (RE/RS, a. I, n. 4, março, 1952, p. 18, grifo nosso).

Para seu desenvolvimento utilizaram-se como materiais um frasco de Erlenmeyer de $100 \mathrm{~cm}^{3}$, um tubo de vidro, uma rolha de borracha furada no centro, um termômetro e duas vasilhas com água fervente e fria, conforme Figura 4. Observou-se que essa experimentação apresenta maior risco se comparada com as demais, pois necessita-se de água quente. Contudo, a revista demarca que seja feita em formato de demonstração, ou seja, o professor é quem desenvolve o experimento.

Figura 4 - llustração da experimentação "Como trabalha um termômetro", da RE/RS.

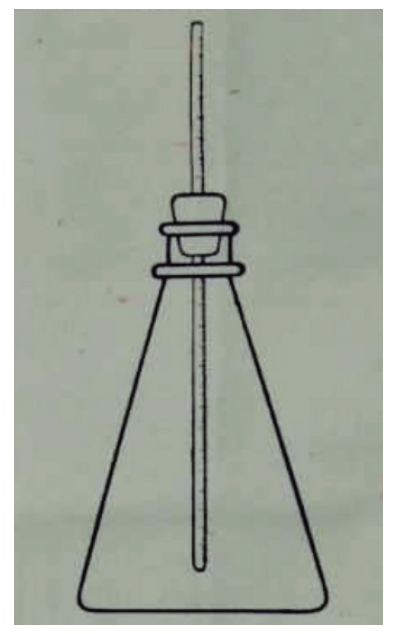

Fonte: Revista do Ensino (a. I, n.4, mar., 1952, p. 18).

0 conceito de temperatura pode ser explorado individualmente ou integrado a mais de uma componente. Dentre suas definições, Mortimer e Amaral (1998) consideram que a temperatura se relaciona a associação da medida de Energia cinética e ao movimento aleatório das partículas de um determinado sistema físico. 0 equilíbrio térmico é dado quando os dois sistemas se encontram na mesma temperatura não havendo mais transferência de calor. Quando dois sistemas se encontram com temperaturas distintas, o que possui maior, fornece energia em forma de calor para o de menor temperatura.

No caso da experimentação supracitada, assim como as demais deste conteúdo, verificou-se que a Temperatura foi desenvolvida de forma isolada, apenas com o intuito de que os estudantes percebessem o funcionamento do termômetro. 
Já no ramo da Mecânica foram detectadas experimentações sobre alavancas, equilíbrio e forças, sendo um dos exemplos apresentado em Maio de 1954:

[...] alavancas - usar uma régua graduada de $30 \mathrm{~cm}$ (ou maior, se possível); prendendo a porção média com auxílio de um barbante ou um prego, colocar massas iguais penduradas a igual distância do ponto de aplicação, e a seguir em distâncias desiguais para verificar o princípio do equilíbrio: "o momento da potência é igual ao momento da resistência, quando a alavanca está em equilíbrio" (o momento da potência é igual ao produto da potência pelo respectivo braço - este é a distância entre o ponto de apoio e o ponto de aplicação da potência) (RE/RS, a. III, n. 22, maio, 1954, p. 14).

Deveriam ser utilizados uma régua, barbante, prego e objetos com diferentes massas para formar uma estrutura igual à da Figura 5. Percebeu-se que esses materiais podem ser encontrados facilmente nos estabelecimentos comerciais ou até mesmo nas residências dos estudantes e do professor, não necessitando de aparato laboratorial.

Figura 5 - Ilustração da experimentação sobre Mecânica, contida na RE/RS.

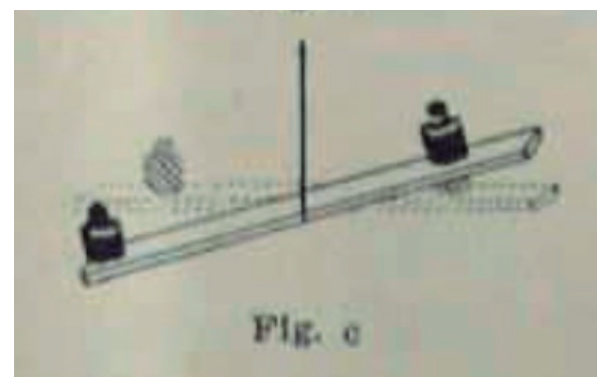

Fonte: Revista do Ensino (a. III, n. 22, maio, 1954, p. 14)

Semelhante a experimentação "Como funciona um termômetro", nessa também o enfoque era delimitado somente a conteúdos de Física, pois abordava as alavancas como princípio de equilíbrio. Segundo Videira (2011), a Mecânica pode ser conceituada como o ramo da Física que se ocupa a estudar e analisar o movimento e o repouso dos corpos num dado sistema. Em outras palavras, "[...] é a ciência do movimento; [...] descreve, completamente e da maneira mais simples possível, os movimentos produzidos na natureza" (Ibid., p. 617).

Por fim, no conteúdo de Acústica, identificou-se um compilado de quatro experimentações em Agosto de 1959, três consistiam no uso do violino para observação da propagação do som e outra utilizava um piano. Essas propostas mostram a possibilidade da inserção de instrumentos musicais nas aulas de Ciências.

Destaca-se que a Música fazia parte do currículo de algumas escolas na década de 1950, tendo, inclusive, seções na RE/RS. Contudo, essa prática não é uma novidade do século XX. Berkovits, pesquisador da Teoria de Supercordas, destaca que na época de Kleper (1571-1630) já haviam registros de que os Físicos detinham conhecimentos musicais com a finalidade de compreender determinados fenômenos físicos, como o som (ALISSON, 2018). Assim, a música e a ciência entrelaçavam-se, já que por meio da sonoridade muitos conceitos eram estudados. 


\section{CONSIDERAÇÕES FINAIS}

Frente às análises realizadas neste estudo, identificou-se que as propostas didáticas de experimentações eram apresentadas com frequência pela RE/RS no período de 1951-1961, pois as seções analisadas estavam presentes em $82 \%$ dos exemplares, porcentagem que pode ser superior, visto que, algumas edições do RDT estavam incompletas.

Verificou-se predominância de experimentações com caráter empirista (86\%), pautadas em registros sistemáticos, replicabilidade e direcionadas a observação. Geralmente, a revista se detinha a detalhar minuciosamente os materiais (com o quê ensinar) e sua execução (como ensinar), tendo como finalidade a comprovação da teoria.

Contudo, as seções temáticas de Março de 1955, Outubro de 1956 e Março de 1958 (água, solo e respiração, respectivamente) indicam que a multi e a interdisciplinaridade poderiam ser aplicadas no Ensino de Ciências, mesmo que ainda não recebessem essa denominação, tampouco fossem 0 foco de estudo dos pesquisadores da época. Já o artigo do exemplar de Outubro de 1959, que defende que as experimentações deveriam ser contextualizadas pelo professor e orientadas por questões-problema, configura-se como um discurso atemporal, sinalizado pela RE/RS na década de $1950 \mathrm{e}$ defendido por pesquisadores contemporâneos como Galiazzi e colaboradores (2001), Delizoicov (1991) e Rosito (2008).

Possivelmente a diversidade e a não linearidade dos experimentos (todos com ou sem contextualização, questões problemas, dentre outras características) ocorre-se, pois, vários profissionais contribuíam com a RE/RS, tais como, professores da Secretaria da Educação, da Universidade de Porto Alegre e das escolas públicas e privadas (FRAGA, 2017).

Inferiu-se também, que as edições que apresentavam propostas destinadas a Biologia traziam até três experimentos, enquanto que, as de Química e as de Física, geralmente, eram constituídas por compilados de quatro ou mais. Mesmo assim, o quantitativo da primeira foi superior as demais, total de 56 experimentos, 47\%. Supõe-se que a expressividade da Biologia se justifique, pois, os Ensinos Primário e Pré-primário eram o foco da RE/RS, sendo os conteúdos de Física e Química normalmente abordados com mais intensidade no último ano do curso Ginasial. Segundo Bastos (2005), a ampliação da linha editorial para outros níveis se deu a partir da década de 1970, com o surgimento do $1^{0} \mathrm{e}$ $2^{0} \mathrm{grau}$, estabelecidos pela Lei de Diretrizes e Bases.

Dos 120 experimentos, apenas dois apresentavam o público-alvo ( $2^{\mathrm{a}}$ série do primário). Contudo observou-se que os termos criança e crianças (no plural) estavam presentes em diversas experimentações, 0 que reforça que a maioria era destinada a esse público. Ao classifica-las e destacar seus conteúdos, verificou-se o predomínio da Zoologia, Botânica, Propriedades da Matéria, Termologia e Mecânica. A ausência de experimentos destinados aos domínios da microfísica, microquímica e microbiologia mostram o quanto essas áreas evoluíram nas últimas décadas, estando inclusive, inseridas nos currículos atuais.

Por fim, destaca-se que a RE/RS se preocupava com a realidade do professorado gaúcho e brasileiro, pois as experimentações, geralmente, utilizavam materiais baratos e de fácil acesso. A maioria não necessitava de aparato laboratorial ou de local específico para realização, podendo ser desenvolvida em diversos ambientes. As seções analisadas demonstram uma diversidade de experimentações que serviram de guia e suporte para muitos professores em sua época de circulação e que, após inventariadas, podem ser aprofundadas em estudos futuros, adaptadas e (re)aplicadas em sala de aula. 


\section{REFERÊNCIAS}

ALISSON, Elton. Música em supercordas. Fundação de Amparo à Pesquisa do Estado de São Paulo, 14 mar. 2018. Disponível em: https://bit.ly/3f1lUja. Acesso em: 30 jun. 2020.

ALVES, Sílvia Mónica Azevedo. Ensino experimental das ciêmncias no $1^{\circ}$ CEB: estudo dos fenómenos de mudança de estado físico da água. 2013. 125 f. Dissertação (Mestrado em Estudos da Criança) - Universidade do Minho, Instituto de Educação, Braga, Portugal. 2013.

BASTOS, Maria Helena Câmara. As Revistas Pedagógicas e a Atualização do Professor: a Revista do Ensino no Rio Grande do Sul (1951 - 1992). In: BASTOS, Maria Helena Câmara; CATANI, Denice Barbara. Educação em revista: a imprensa periódica e a história da educação. 1. ed. São Paulo: Escrituras, 1997, p. 47-76.

BASTOS, Maria Helena Câmara. A Revista do Ensino do Rio Grande do Sul (1929 - 1942): o novo e o nacional em revista. Pelotas: Seiva, 2005.

BELTRAN, Maria Helena Roxo História da ciência e ensino no laboratório: considerações sobre experimentação, visão de ciência e replicação de experimentos históricos no ensino de química. In: ENCONTRO NACIONAL DE PESQUISA EM EDUCAÇÃO EM CIÊNCIAS, 10, 2015, Águas de Lindóia, SP. Anais [...]. Águas de Lindóia, ENPEC, 2015.

BICA, Alessandro Carvalho. A Organização da Educação Pública Municipal no Governo de Carlos Cavalcanti Mangabeira (1925-1929) no município de Bagé/RS. 2013. 301 f. Tese (Doutorado em Educação) - Universidade do Vale do Rio dos Sinos, São Leopoldo. 2013.

BICA, Alessandro Carvalho; RODRIGUES, Tobias de Medeiros; GERVÁSI0, Simôni Costa Monteiro. Tatu Magazini: os modos de ser e fazer do Repositório Digital Tatu. Revista História da Educação, v. 23, p. 1-18, 2019.

CUNHA, Isabel. Análise documentária. In: SMIT, Johanna W. (Coord.). Análise documentária: a análise da síntese. 2. ed. Brasília: IBICT, 1989, p. 39-62.

DELIZOICOV, Demetrio. Conhecimento, tensões e transições. 1991. 219 f. Tese (Doutorado em Educação) - Faculdade de Educação da Universidade de São Paulo, São Paulo. 1991.

DENZIN, Norman K.; LINCOLN, Yvonna (Orgs). Planejamento da pesquisa qualitativa: teorias e abordagens. 2 ed. Porto Alegre: ARTMED, 2006.

DEUTSCH, David. The fabric of reality. New York: Alan Lane, 1997.

DUARTE, Cláudia Glavam. A - realidade - nas tramas discursivas da educação matemática escolar. 2009. $191 \mathrm{f}$. Tese (Doutorado em Educação) - Programa de Pós-Graduação em Educação, Universidade do Vale do Rio dos Sinos, São Leopoldo. 2009.

FARIA, Joana Borges de. Os quadros parietais nas escolas do Sudeste brasileiro (1890 1970). 2017. 332 f. Tese (Doutorado em Educação: História, Política e Sociedade) - Programa de Estudos Pós-Graduados em Educação: História, Política Sociedade, Pontifícia Universidade Católica de São Paulo, São Paulo. 2017. 
FAZENDA, Ivani Catarina Arantes. Interdisciplinaridade: História, Teoria e Pesquisa. 18. ed. São Paulo: Papirus, 2012.

FONSECA, Rúbia Santos; VIEIRA, Milene Faria. Coleções botânicas com enfoque em herbário. Viçosa, MG: Editora UFV, 2015.

FRAGA, A. S. de. Trajetórias de alunas-mestras a professoras intelectuais da Educação no Rio Grande do Sul (1920 a 1960). 2017. 215 f. Tese (Doutorado em História) - Programa de Pós-Graduação em História, Pontifícia Universidade Católica do Rio Grande do Sul, Porto Alegre. 2017.

FRANCISCO JÚNIOR., Wilmo. E. et al. Experimentação Problematizadora: fundamentos teóricos e práticos para a aplicação em salas de aula de ciências. Química Nova na Escola, n. 30, p. 34-41, nov. 2008.

GALIAZZI, Maria do Carmo et al. Objetivos das atividades experimentais no Ensino Médio: a pesquisa coletiva como modo de formação de professores de Ciências. Ciência e Educação, v. 7, n. 2, p. 249-263, 2001.

GIL, Antônio Carlos. Como elaborar projetos de pesquisas. 4. ed. São Paulo: Atlas, 2002.

GIL, Antônio Carlos. Métodos e técnicas de pesquisa social. 6. ed. São Paulo: Atlas, 2008.

GODOY, Arilda Schmidt. Pesquisa qualitativa: tipos fundamentais. Revista de Administração de Empresas, São Paulo, v. 35, n. 3, p, 20-29.

JAPIASSÚ, Hilton. Interdisciplinaridade e Patologia do Saber. Rio de Janeiro: Imago, 1976.

KRASILCHIK, Myriam. Reformas e realidade: 0 caso do ensino das ciências. Perspectiva, São Paulo, v. 14, n. 1, jan./mar. 2000.

LIMA, Luiza Renata Fêlix de Carvalho. Ensinando na cozinha! Investigando a prática pedagógica de professores e a experimentação nas séries iniciais. 2016. 132 f. Dissertação (Mestrado em Educação em Ciências) - Programa de Pós-Graduação Mestrado em Educação em Ciências, Universidade Estadual de Santa Catarina, Santa Catarina. 2016.

LOPES, Eliane Marta Teixeira; GALVÃO, Ana Maria de Oliveira. História da Educação. Rio de Janeiro: DP\&A, 2001.

MAGALHÃES JÚNIOR, Carlos Alberto de Oliveira; PIETROCOLA, Maurício; ORTÊNCIO FILHO, Henrique. História e características da disciplina de ciências no currículo das escolas brasileiras. Educere - Revista da Educação, v. 11, n. 2, p. 197-224, 2011.

MARCONI, Marina de Andrade; LAKATOS, Eva Maria. Metodologia cientifica: ciência e conhecimento científico, métodos científicos, teoria, hipóteses e variáveis. 5. ed. São Paulo: Atlas, 2007.

MARTINS, Ubiraiara. A. Coleção taxonômica. In: PAPAVERO, Nelson (Org.). Fundamentos práticos de taxonomia zoológica: coleções, bibliografia, nomenclatura, 2. ed. São Paulo: UNESP-FAPESP. 1994.

MORTIMER, Eduardo Fleury; AMARAL, Luiz Otávio F. Quanto mais quente melhor: calor e temperatura no ensino de termoquímica. Revista Química Nova na Escola, n. 7, p. 30-34, maio, 1998. 
OLIVEIRA, Jane Raquel Silva de. Contribuições e abordagens das atividades experimentais no ensino de ciências: reunindo elementos para a prática docente. Acta Scientiae, Canoas, v. 12, n. 1, p. 139-153, jan./jun., 2010.

PÁDUA, Elisabete Matallo Marchezine de. Metodologia da pesquisa: abordagem teórico-prática. 2. ed. Campinas: Papiros, 1997.

PEREIRA, Luiz Henrique Ferraz. Os discursos sobre a matemática publicados na revista do Ensino do Rio Grande do Sul (1951-1978). 2010. 315 f. Tese (Doutorado em Educação) - Programa de Pós-Graduação em Educação, Pontifícia Universidade Católica do Rio Grande do Sul, Porto Alegre. 2010.

PIMENTEL, Alessandra. 0 método da análise documental: seu uso numa pesquisa historiográfica. Cadernos de Pesquisa, n. 114, p. 179-195, nov., 2001.

ROSITO, Berenice Alvares. 0 ensino de ciências e a experimentação. In: MORAES, R. Construtivismo e ensino de ciências: reflexões epistemológicas e metodológicas. 3. ed. Porto Alegre: EDIPUCRS, 2008, p. 195-208.

SALVADEGO. W; LABURÚ. C; BARROSA. M. Uso de atividades experimentais pelo professor das Ciências Naturais no Ensino Médio, relação com o saber profissional. In: CONGRESSO PARANAENSE DE EDUCAÇÃO EM QUÍMICA, 1, 2009, São Paulo, SP. Anais [...]. São Paulo: CPEQUI, 2009.

SANTOS, Newton Dias dos. Práticas de Ciências: Guia do Ensino Elementar. Editora Olímpia, 1957.

SARDAGNA, Helena Venites. Práticas normalizadoras na educação especial: um estudo a partir da rede municipal de ensino de Novo Hamburgo, RS (segunda metade do século XX início do século XXI). 2008. $315 \mathrm{f}$. Tese (Doutorado em Educação) - Programa de Pós-Graduação em Educação, Universidade do Vale do Rio dos Sinos, São Leopoldo. 2008.

SILVA, Thabatta Almeida Gonçalves da; CORRÊA, Beatriz de Castro; MATOS, Guilherme Inocêncio. Desenvolvimento e organização de coleção zoológica didática no CEFET/RJ: desafios, possibilidades e primeiras aplicações. Revista da Associação Brasileira de Ensino de Biologia (SBEnBI0), n. 7, p. 7151-7161, 2014.

STOLL, Vitor Garcia; BICA, Alessandro Carvalho; COUTINHO, Cadidja. Levantamento preliminar das seções do Ensino de Ciências na Revista do Ensino do Rio Grande do Sul (1951-1961). In: ENCONTRO DA ASSOCIAÇÃO SUL-RIO-GRANDENSE DE PESQUISADORES EM HISTÓRIA DA EDUCAÇÃO, 25, 2019, Bagé, RS. Anais [...]. Bagé: ASPHE, 2019.

VIDEIRA, Antônio Augusto Passos. Kirchhoff e os fundamentos da mecânica. Revista Scientae Studia, v. 9, n. 3, São Paulo, 2011.

WESCHENFELDER, Noeli Valentina. Uma história de governamento e de verdades: educação rural no RS 1950/1970. 2003. 207 f. Tese (Doutorado em Educação) - Programa de Pós-Graduação em Educação da Faculdade de Educação, Universidade Federal do Rio Grande do Sul, Porto Alegre. 2003.

RECEBIDO EM: 05 set. 2020

CONCLUÍDO EM: 20 abr. 2021 